\title{
Graffiti in China - Chinese Graffiti?
}

\author{
MINNA VALJAKKA
}

\begin{abstract}
This article focuses on the emergence of graffiti in Beijing and Shanghai as an intriguing part of the contemporary art scene. Approaching graffiti through the framework of visual culture and analyzing both the visual and social aspects of creating graffiti images, I argue that contemporary graffiti in these cities can be regarded primarily as creative self-expression emphasizing aesthetic intention and a renaming process, not as vandalism. Deriving primarily from information gathered during my fieldwork in Beijing and Shanghai, I also discuss the development of graffiti in China and its characteristics. In the Euro-American context, graffiti is still commonly regarded as criminal activity that destroys public property. This allegation, however, fails to take into account how the international graffiti culture has become an enduring genre of art with strong emphasis on style and aesthetic evaluation. Although creating graffiti is a controversial issue in China also, graffiti nevertheless exists, especially in the so-called art areas (districts known for their numerous art galleries, artist studios, art-related activities and, occasionally, art museums), or in the surrounding neighbourhoods.
\end{abstract}

Keywords: contemporary graffiti, graffiti images, contemporaryart, artareas, visual culture.

\section{Introduction}

'Without graffiti, cities are just grey and dead.' Zhang Dali, 2008.

Graffiti has been a vigorously spreading phenomenon, expanding around the globe since the 1970s. Although artistic creativity is an essential feature in graffiti, it has been primarily regarded as an illegal and destructive subcultural form. Academic studies discussing both the historical development and sociocultural context of graffiti in the United States or in Europe have been met with growing interest. Even more abundantly available are photographic compilations of the graffiti in one city or country or introducing the international scene including examples from various countries (see e.g., Barthelmeh 1982; Cooper \& Chalfant 1984; Huber 1986; Ganz 2004; Sanada 2007; Gastman, Neelon \& Smyrski 2007; Grody 2007). Unfortunately, China has not enjoyed as much attention yet and photographs of Chinese graffiti are seldom included in these 
publications. One interesting exception is the recently published Graffiti Asia (Sanada \& Hassan 2010). Furthermore, academic research focusing on contemporary graffiti in China has not yet been published. There are at least two master's of art theses by Chinese students discussing the origin of graffiti in the United States, and briefly on its emergence in China (Wang 2007; Wei 2008), but as far as I know, graffiti has not been a topic of a PhD thesis or other scholarly research in China. Three academic papers focusing on the contemporary artist Zhang Dali's (张大力 b. 1963) early involvement in the graffiti scene provide valuable information on the initial phase of contemporary graffiti in China (Wu 2000; Marinelli 2004 , 2009). These papers, however, fail to address any broader aspects of the sociocultural context or the history of graffiti in China.

This article aims to compensate for this lack of academic interest. It is based on new information collected during my periodic fieldwork conducted between 2006 and 2009 in Shanghai and Beijing. To uncover the state of graffiti, I started to document graffiti images in situ, creating a collection of several hundred photographs. In addition, I gathered information from articles published in newspapers and popular journals, made personal observations, and conducted interviews and informal discussions with writers, ${ }^{1}$ art students, critics and people visiting or working in the art areas. Because of the controversial attitudes towards graffiti and the unfamiliarity with this novel phenomenon, it was not always easy to get people to talk about graffiti. In addition, the graffiti scene is in continuous flux, and as is often the case in China, timing interacts with the level of sensitivity of various issues. In June 2008 my intention was to conduct many in-depth interviews with writers, but due to the upcoming Olympic Games, supervision of graffiti had tightened and it was surprisingly difficult to persuade writers to be interviewed, either in person or through email questionnaires. However, visual and written materials by Chinese writers, such as filmed interviews, are abundant and available on the Internet and they have been beneficial for this research. In addition, short popular articles (see e.g., Li \& Lai 2006; Lally 2007; Lipman 2007; Freundl 2008) and videos available online (see e.g., Journeyman pictures 2000; detroitshowtyme 2007; 56minus1 2008), have provided useful information about the graffiti scene in China. As a result, by combining different studies about Euro-American graffiti as a comparative framework, and drawing from these various primary sources, my aim is to discuss the situation of contemporary graffiti in China and how the Chinese sociocultural context has governed its development. 
Most studies on graffiti in the Euro-American context concentrate strongly on the social aspects of graffiti and represent anthropological or ethnographical case studies (see e.g., Austin 2001; Brewer \& Miller 1990; Caffee 1993; Castleman 1982; Feiner \& Klein 1982; Ferrell 1993; Lachmann 1988; Macdonald 2002; Rahn 2002; Schacter 2008). Although the sociological approach is beneficial for understanding graffiti as a form of urban subculture, I argue that it is essential to include the visual aspects in research. The lack of attention to the content and style of the graffiti images by academic researchers hinders the full understanding of the situation. By combining both sociological and visual approaches, as done by Jack Stewart (1989), Staffan Jacobson (1996) and Rafael Schacter (2008), it is possible to provide an in-depth analysis of the contemporary graffiti scene. Therefore I have found the interdisciplinary approach of visual culture most beneficial for studying the emergence of graffiti in China.

Theoretical and methodological discussions on issues of visual culture have been numerous and various definitions have been developed for the primary concepts (see e.g., Dikovitskaya 2005: 1-84; Elkins 2003: 1-62; Mirzoeff 2002). When considering contemporary graffiti as an essential part of the visual culture, I consider Irit Rogoff's (2002) approach most useful. She indicates that, in addition to the study of images, the field of visual culture includes questions of vision, visual production, power relations and aesthetic values. Furthermore, for Rogoff, the visual culture approach allows for an exploration of the ways in which cultural meanings are constructed in an intertextual sphere where

images, sounds and spatial delineations are read on to and through one another, lending ever-accruing layers of meanings and of subjective responses to each encounter we might have with film, TV, advertising, art works, buildings or urban environments (2002: 24).

Combining Rogoff's understanding of visual culture with a trichotomy of images, in which images can contain writing, notation and pictures - or any combination of these-suggested by James Elkins (1999: 82-89), it is possible to regard contemporary graffiti, as graffiti images, and as an essential part of this multifaceted intertextual sphere of visual culture. Consequently, the visual aspects of the images, such as format and content, are extremely important features to be taken into account in the research of visual culture. To further clarify the impact of these visual elements in graffiti, I will apply integrational semiology introduced by Roy Harris (1995) and demonstrate how visual aspects, such as style and materials, both reveal and interact with the motivation, creation, reception and acceptance of graffiti images. 
Due to the scarcity of previous research on and documentation of graffiti in China, I will first address the question of graffiti as images and clarify the concept of 'contemporary graffiti' as a new form emerging in China. Second, I will outline the specific features of the historical development of graffiti as artistic self-expression in China, although a detailed history is not within the scope of this article. My understanding of artistic self-expression in graffiti derives from Rafael Schacter's (2008) suggestion that graffiti images are 'personification of the self', filled with aspects of self and private emotions. Schacter argues that every image, $\operatorname{tag}^{2}$ or stencil can be regarded as a form of 'distributed personhood'13 (Schacter 2008: 37-39). For Schacter, graffiti is clearly artistic creation, expression of private emotions and thoughts. I will use the concept of artistic/creative self-expression for independently created graffiti to emphasize that they are made for expressing private purposes, instead of creating images according to a pre-established ideology or a political programme set from outside of the graffiti scene. Third, because I suggest that one major difference between the Chinese graffiti scene and the Euro-American one is the strong relationship between graffiti and contemporary arts in China since the emergence of graffiti there, I will discuss this interaction in detail. I will also address the important question of illegality of graffiti, which has an impact on its tolerance by officials. Finally, I will briefly discuss how motivation is related to the content of graffiti images.

The main focus of this study is the graffiti scenes of Shanghai and Beijing, which I have been able to research myself, but I will include information on other cities when possible. My new contribution to this unexplored field is to suggest a theoretical framework that would combine both visual and social characteristics of Chinese graffiti, outline major features of historical development, and encourage further research on this theme deriving from specific Chinese socio-political and cultural contexts.

\section{The Importance of 'Image' in the Graffiti Scene}

Previous studies on graffiti in the Euro-American context provide valuable observations on graffiti as a social phenomenon despite their lack of visual analysis. For example, Nancy Macdonald's (2002) ethnographic research on graffiti in London and New York challenges some of the previous perceptions. Her main argument is that Marxist theories that regard subculture as class struggle are not appropriate for an under- 
standing of the motivations in graffiti. Instead, she argues that graffiti is used primarily to construct masculinity and identity among young male writers because it is seen as a war against the authorities. Similar notions of graffiti as a struggle for public space and as a form of resistance are commonly expressed in the Euro-American context (see e.g., Austin 2001: 4-5; Rahn 2002: 175-177).

Although the content of the graffiti might not be a primary concern when investigating the motivations of writers, it has nevertheless become evident that different forms of graffiti cannot be considered separately, as Jean Baudrillard (1993) has done. For Baudrillard, 'graffiti' denoted only written names, which meant nothing and therefore could be considered 'empty signifiers'. Writing names resulted in 'a kind of riot of signs' in a city, bearing political significance but lacking any content and meaning. Contrary to graffiti, frescoes and murals made without official commission were 'spontaneous art works' and they usually have a revolutionary message, but emphasizing aesthetic criteria in murals can reduce their political articulation (Baudrillard 1993: 76-83). However, as Rafael Schacter (2008) has shown, the creation of the various forms of graffiti is a highly interdependent action and these forms - also the written names, the tags - are all part of the process of self-expression. The questions as to what is written/drawn/painted on the walls and how, are at least equally important as the more common questions of who and where. Even tags have meaning, and contrary to Baudrillard's claim that these names 'make no claim to an identity or a personality' (1993: 79), they have become known as the primary signifier of a writer's identity, which is carefully designed and expressed with detailed selection of writing style, format and even colour.

It is nevertheless important to remember that not all graffiti is created as a political action or struggle against officials, as is often suggested. Legitimate forms of graffiti, such as artworks displayed in galleries and commissioned murals to decorate specific public spaces or private interiors, have existed in Europe and the United States since the 1970s. In addition, the content of the graffiti - the subject-theme - is highly relevant for further interpretation of the action. The content can be political or non-political. Furthermore, even if the content is political, it can be antiEstablishment or pro-Establishment. All these variations in the content have an impact on the final meaning of the graffiti and therefore I argue that to see all graffiti as a form of resistance or political action is an oversimplification of reality. To clarify these differences it is essential to pay attention to the visual aspects of graffiti, the images themselves. 
The earliest study on graffiti in the United States combining both sociological and visual approaches was done by Jack Stewart (1989). Afterwards, the significance of visual aspects was brought up by Staffan Jacobson (1996) and Rafael Schacter (2008). Contrary to the majority of studies on graffiti, Schacter, in his article about graffiti in London, focused more on the graffiti itself, on the agency of the images, rather than on the writers. For Schacter the agency of the images, imposed by the writers and interiorized by the viewers, means that these images can reveal the personality and the identity of the writers and, furthermore, attract, capture and enthral the viewers. His main argument is that graffiti images are a powerful and multifaceted form of agency and physical embodiment of the writer. Schacter's study provides new and intriguing aspects for the research of graffiti primarily as a form of artistic creativity that is used for revealing personal identity, feelings and even one's nationality in a multicultural environment, such as the graffiti scene in China.

But can graffiti, as Schacter has suggested, be considered images? Graffiti has been defined primarily as 'writing' because it was originally focused on words. However, pictures have become an important part of graffiti, and very often graffiti today consists mainly of pictures, except for a tag as a signature. Moreover, various new techniques, such as printed posters and stickers have become popular, giving more emphasis to the act of drawing and painting rather than writing. As a result, to denote graffiti as 'writing' has actually become quite problematic. Also, the use of the concept of 'image' varies among scholars and disciplines revealing very ambiguous definitions. W. J. T. Mitchell (1986) has provided a good overview of the multifaceted usage of the term 'image', and he has aimed to clarify the concept by creating 'the family of images', which consists of five categories: graphic, optical, perceptual, mental and verbal images (pp. 9-11). However, his approach does not take into account 'writing' as an image. For Mitchell, the concept of 'graphic image' denotes physical pictures, portraits and statues, but not written text. How can we deal then with various forms of visual images that are based on the interaction of picture and text, such as traditional Chinese ink paintings in which the meaning is derived from the interaction of poetry, calligraphy and painting? Moreover, the same method, combining written text and picture into an image, has been an essential part of the Euro-American graffiti scene. Consequently, a more appropriate understanding of images in contemporary graffiti is provided by James Elkins (1999), when he defines images as 'patterns on surfaces' (p. 256). 
Elkins has focused only on material representations and he suggests a trichotomy of an image as writing, notation and picture, which can include far more varied representations in the domain of images and the 'pictographic and ideographic elements in writing' (p. 4). This approach is also based on the notion that usually an image is a combination of two or all three of these categories. ${ }^{4}$ Deriving from the framework provided by Elkins, I suggest that contemporary graffiti that includes either writing or pictures or both, can therefore be considered 'images'. Further, to clarify that these images are material representations, not mental or immaterial ones, I suggest the concept of graffiti image, which can then include both pictures and writing, or either one of them.

\section{Traditional vs. Contemporary Graffiti in China?}

The situation of contemporary Chinese graffiti can be approached from two theoretically different directions. One is to suppose that Chinese graffiti is merely a plagiarized form of its Euro-American predecessors. The other is to assume that contemporary graffiti in China is highly dependent on its own sociocultural context and is driven to develop its own forms of expression. Despite being a global phenomenon, graffiti is clearly not homogeneous, and different forms, techniques and motivations have emerged worldwide. When visual systems are transferred from one cultural area to another, the process of transfer is very complex, as art historian John Clark (1998) has shown in his extensive research on the development of modern art in Asia. Partiality and selectivity of assimilation are essential features of all processes of transfer, and even intentions of the visual system can be changed (Clark 1998: 35-38, 49-54). As Clark has indicated, the transfer of a visual system essentially is based on appropriation and cannot be regarded as mere imitation. Consequently, the first assumption, that Chinese graffiti is merely replication, turns out to be a very Eurocentric and naive hypothesis. However, it is essential to acknowledge the interaction between the sending and receiving cultures to exemplify how partial the transfer has been, starting from the application of the concept of graffiti.

In the widest meaning, the word 'graffiti' is used for any kind of writing, inscription or scratching on a wall, or on some other surface, such as a tree or rock. With this denotation, graffiti has existed for centuries all over the world in various forms, including, for example, names, slogans, illustrations, symbols, and epigrams on the streets, in public places, in prisons (see e.g., Stewart 1989: 15-147) and even on religious 
paintings in the fifteenth century (Plesch 2002). Some even suggest that cave paintings could be regarded as graffiti (Ganz 2004: 8).

If one views China from this perspective, then all writings and inscriptions in public spaces should be regarded as graffiti (see Figure 1). The expression is used, for example, for the writing on the summit of Mount Tai, dated 1590 (Clunas 2007: 109). In the same way, tourists' names and comments incised on the Great Wall have been referred to as graffiti (Stewart 1989: 35-37; BBC 2002). If anything written in public is regarded as graffiti, then political slogans and manifestos of the twentieth century written with brush and ink, for example, by Mao Zedong, should also be included in this category. ${ }^{5}$ Similarly, expressing his politically critical views, Tsang Tsou Choi, known as the 'King of Kowloon', has written an uncountable number of long, calligraphic inscriptions with a brush on the streets of Hong Kong for decades (Clarke 2002: 175-184; 2001). With this approach, phone numbers and even the demolition signs, chai (拆), which have been an integral part of Chinese streets lately, would all be graffiti. It has even been suggested that painted phone numbers that are used to advertise the making of false certificates (ban zheng 办证) are 'redolent of graffiti tagging'6 (Borysevicz 2008: 68). However, although this broad historical approach to graffiti suggests a long, unchanged tradition, it nevertheless confuses more than it clarifies. In addition, these various forms of writing in public have not all been considered graffiti in China.

To further analyze the differences, it is useful to adapt the approach of integrational semiology introduced by Roy Harris (1995). Harris's approach provides methods to acknowledge that the motivations, interpretations and outcomes of the process of writing are extremely varied and clearly dependant on the cultural context. The significance of the act of writing can be unrelated to the content, and the mere act in a public space can be seen as a sign of political activism. However, the content of the written sign usually has a clear impact on the significance of the act of writing and vice versa.

Consequently, from the integrational point of view, a written sign is essentially a contextual product and its significance derives from the communication process. The integrational approach includes various communicationally significant features involved both in the act of writing (forming), as well as in the processing of the significance of the written sign. Consequently, systems of writing will vary according to the activity in question, and even the utilization of the graphic space and typography used become relevant features (Harris 1995: 33-37, 50-68). 
FIGURE 1: Bamboo in Daguanyuan, Shanghai, 2001.

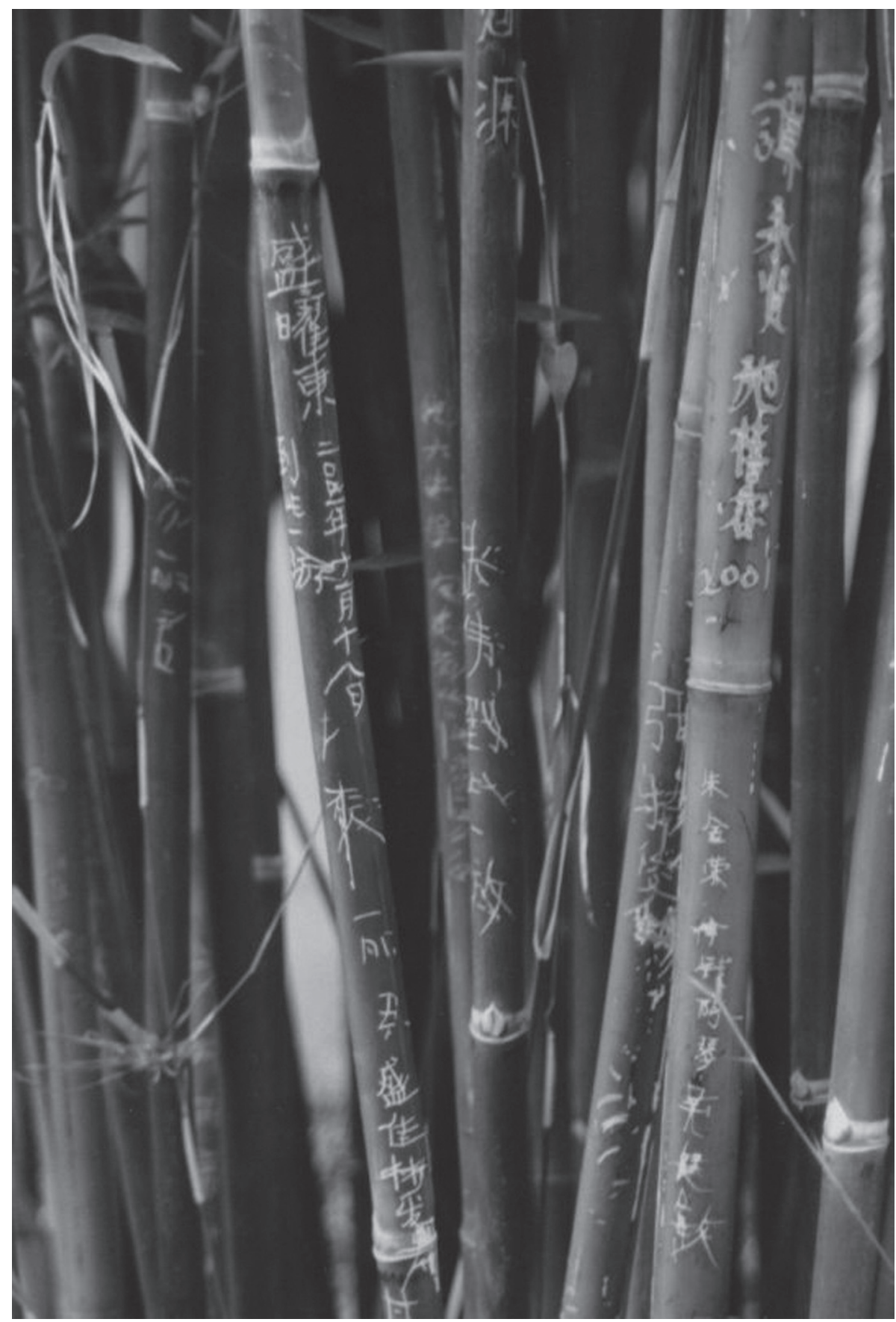

Copyright by the author. 
Extending this approach to contain other acts of visual expression such as painting and drawing, it is possible to clarify how there are actually more differences than similarities to be found if one compares a cave painting made for shamanistic purposes with a casually written text, or rude drawings scratched on prison walls. Similarly, the intention clearly differs when a person inscribes initials into a famous scenic spot or when a writer creates a large, multicoloured piece ${ }^{7}$ after hours of careful design.

Intention has been a crucial feature for Jack Stewart, who has suggested that graffiti done prior to the 1970s can be defined as 'traditional graffiti' because it was made for random public consumption primarily as an anonymous act. It was intended 'to convey a description or a message in a literal sense' with a lack of aesthetic intention or concern for style (Stewart 1989: 15, 146). A major rupture occurred in the history of graffiti starting in the 1960s, and by the early 1970s a new form, 'modern graffiti', was developed on the streets of Philadelphia in the United States. The major distinctive feature of this 'modern graffiti' was the evolution of aesthetic concerns and intentions (Stewart 1989: 148-191, 493). From its birthplace, graffiti spread around the continent and developed vigorously, reaching Europe in the 1980s (Ganz 2004: 126; Ferrell 1993: 10-11). Staffan Jacobson has developed this approach further by suggesting the concept of 'TTP graffiti' (Tags, Throw-ups, Pieces) ${ }^{8}$ as an independent and distinguishable form of graffiti (Jacobson 1996: 10-20, 204-205). Although researchers do not always make a clear distinction between traditional and modern forms of graffiti, they focus on current graffiti as a distinctive form of urban youth culture, different from the long tradition of writing in public (see e.g., Austin 2001; Castleman 1982; Rahn 2002).

Is Jack Stewart's definition of 'traditional' and 'modern' graffiti a useful approach to graffiti in China? The emergence of 'modern graffiti' in the United States is clearly contextually related. In China, the modernization process, both cultural and economic, has been very different from the Euro-American experience. In order to acknowledge the specific development of modernity in non-Western countries, counter- or alternative narratives of modernity have been developed. Haiqing $\mathrm{Yu}$ (2009: 31) has clarified that in China the concept of counter-narratives of modernity has three layers of meaning: 'the state narrative of Chinese socialist modernity, intellectual critiques of the Chinese state and Western narratives of modernity, and popular expressions of Chinese modernity at the everyday level'. Consequently, there are counter-nar- 
ratives of modernity in relation to the West and the counter-narratives of Chinese modernity in relation to the party-state (Yu 2009: 31). As Yu has indicated, the counter-narratives of both modernity and post-modernity are extremely complex phenomena in non-Western countries (pp.32-35).

These counter-narratives are also reflected in the contemporary art scene. Art historian Gao Minglu has suggested that 'in Chinese contemporary art modernism and postmodernism represent false distinction because China did not produce the same modernism that was produced in a different cultural context at another time' (2005: 239). The delineations between 'modern', 'postmodern' and 'contemporary' were lost on the Chinese art scene and furthermore, 'modernity' is not referring to a specific historical time, but more usually to the 'spirit of the times' in China (pp. 43-45). Due to the complexity of the term 'modern' in the Chinese context, and its inappropriateness in the contemporary Chinese art scene, I suggest that a slightly more neutral concept, 'contemporary graffiti', be used for the new form of graffiti in China. With this concept it is possible to reduce the misunderstandings and oversimplifications that could emerge by using the notion of 'modern graffiti' deriving directly from the Euro-American discourse. Moreover, the use of 'contemporary' is more suitable in the context of Chinese graffiti because of its very recent emergence and its close relation to the contemporary art scene. In the Euro-American context, it is, however, meaningful to use the concept of 'modern graffiti'.

\section{Initial Steps}

The development of contemporary graffiti into its new form of artistic self-expression has benefited from the long tradition of public writings in China. In the cultural context of China, writing poems and inscriptions on stones, mountains or other public spaces has been an integral part of the appreciated cultural heritage. Consequently, certain forms of writing in public have been accepted, even valued. However, new socio-political circumstances emerging along with a modern nation in the twentieth century challenged traditions and writing in public became primarily a political act. Especially since the establishment of the new nation as the People's Republic of China, political campaigns utilized and encouraged writings in public places. They have advocated mainly the official doctrines, although for example, the 'big character posters' (dazibao 大字 报), also offer an opportunity for political self-expression within certain 
limits. In addition, an interesting phase of peasant wall paintings as murals decorating public walls occurred at the end of the 1950s in Jiangsu and Zhejiang provinces (see e.g., Galikowski 1998: 86-93).

Nevertheless, neither big character posters nor peasant wall paintings are regarded as a form of graffiti in China, although they also represent visual expression in public and can even include aesthetic intentions. With Jacobson's (1996) approach of TTP graffiti, we could claim that these are not graffiti due to the material and format. Neither the big character posters nor peasant wall paintings used spray paint or marker pen. However, new forms of contemporary graffiti in China include posters and stickers, so the format and material can no longer be the distinguishing feature. It could then be suggested that an obvious difference is the controversial status of contemporary graffiti, whereas political wall paintings and slogans were officially encouraged. Nonetheless, the emergence of commissioned graffiti has supported the notion of a 'legal graffiti' developing in China, and the argument of illegality has become obscured. Besides the aesthetic intention, what might then be a differentiating feature?

As Stewart suggests, traditional graffiti has primarily been anonymous (Stewart 1989: 15). One of the major features in modern graffiti in the United States has been the creating and making of a specific name for oneself. Writers do not use their real names, but instead they create a new name that is used as a writer's tag, which is essential for every writer. Renaming oneself and developing a specific identity based on the tag and an original style is one of the basic motivating factors behind modern graffiti. In the early years of graffiti, the identification could be based on the writer's locality or ethnic background (see e.g., Austin 2001: 42-46; Castleman 1982: 71-76; Rahn 2002: 4, 65-66). Tags chosen today, including those used by writers in China, are usually based on personal preferences and occasionally have a specific meaning, such as 'Rois', which denotes 'king' in French (Rois, interview, 29 June 2008). Like Euro-American writers, it is possible for their Chinese counterparts to have more than one writer name (see e.g., Popil 2009).

Creating modern graffiti clearly is aimed at the self-construction of oneself as a writer. Borrowing a writer's own words, 'writing your name identifies who you are' (quoted in Castleman 1982: 76) and writing can therefore become a 'performance of another self' (Austin 2001: 48). However, for some Chinese writers, graffiti has become closely intertwined with their everyday lives and the tag names are used, for example, as a design brand. Besides individual names, identity is also constructed in 
relation to other writers based on both collaboration and competition in the community. Writers form crews, groups of affiliated writers, such as MIG in Shanghai and BJPZ in Beijing, which then work together to create pieces and strengthen communal identity as a specific group. Applying Harris's concept of 'forming' as 'any activity or sequence of activities by means of which a written form is produced' (Harris 1995: 64), it can be claimed that in contemporary Chinese graffiti, aesthetic intentions involved in stylistic choices and the use of tags, which reveals the renaming process, are two important features of forming graffiti. As such, it is clearly distinguishable from other, traditional forms of graffiti still visible today, such as incised inscriptions, demolition signs or phone numbers, which clearly lack these new features.

By this definition, contemporary Chinese graffiti is a relatively young phenomenon, emerging gradually since the mid-1990s, but gaining visibility only in the twenty-first century. Contemporary graffiti was introduced to Beijing by Zhang Dali when he returned from Bologna to Beijing in 1995. In Italy, Zhang made his first graffiti of a profile of a bald-headed man. After returning to Beijing, Zhang continued to paint this figure on the walls of hutongs, old narrow alleys of Beijing, doomed to be demolished, using his tag 'AK-47'. In 1998, Zhang further developed his idea of a spray-painted graffiti image; he decided to chisel holes shaped exactly like the bald-headed man into the walls of partially demolished buildings. Together this uncountable number of graffiti images and installations constituted a series of artworks entitled Dialogue (Duihua 对话) (Zhang, interview, 20 June 2008; see also Zhang 1999; Marinelli 2004). In an interview, Zhang Dali explained that this graffiti image is actually his own self-image. Zhang also emphasized that writing on the wall with a brush is not really graffiti, but instead, true graffiti requires the use of spray paint and therefore he was the first one to do graffiti in Beijing. It was not until the mid-1990s that spray paint could be bought in China. Zhang continued to make graffiti images until 2005, when he decided to concentrate on other forms of contemporary art (Zhang, interview, 20 June $2008^{10}$ ).

Was Zhang Dali really the first writer in China? He was the first in Beijing, and the one who became most famous for it. Zhang might not be the first because before him there was a writer called MCRen (MC仁) active in Hong Kong (Soos, interview, 13 June 2008 ${ }^{11}$ ). MCRen actually claims that he was the first writer in Asia (MCRen 2007). Obviously, MCRen does not consider the 'King of Kowloon' with his brush technique a true writer. It seems that for both MCRen and Zhang Dali there is a 
clear distinction between traditional writing in public and 'true' graffiti using new materials. Based on the idea of contemporary graffiti focusing primarily on aesthetic criteria and renaming, it is also possible to argue that, although the writings done by the 'King of Kowloon' are visually compelling, they do not represent contemporary graffiti because they lack both the aesthetic intention and renaming oneself. ${ }^{12}$

Who the first Chinese writer was remains open to dispute, since, according to the documentary, Great Walls of China (Pearl Channel 2007), there might have been some writers active in Hong Kong even before the mid-1990s. Furthermore, before 1997, Hong Kong was still governed by the British, so even if contemporary graffiti existed before the transfer of sovereignty, it provokes a dilemma of ethnicity and place. Indeed, can the graffiti in Hong Kong be regarded as part of the 'Chinese graffiti scene' before 1997 ?

Despite a strong tradition of writing in public in China, the contemporary form of graffiti could not have emerged until the socio-political changes that opened China to Euro-American influences starting in the 1980s. Economic and social development in the 1990s enabled more diversified cultural industries and artistic experiments, such as new media art to emerge as self-expression. It allowed Zhang Dali to develop his Dialogue series, and it also made it possible to learn about Euro-American graffiti from the Internet and foreign publications and gradually to obtain the materials for creating graffiti. In the twenty-first century, the international interest in contemporary Chinese art created demand and opportunity in specific art areas filled with galleries and artists' studios. It can also be claimed that the glamour of the globally known contemporary Chinese artists, the new 'superstars of China', has made art more compelling as a career choice. The popularity of contemporary art created by the international art market transformed the art areas into appealing touristic attractions where people interested in creative self-expression, such as artists, designers and writers, all wish to be seen.

Consequently, the form, the space, the agents and the intentions of graffiti have clearly changed in recent years and contemporary graffiti is undoubtedly different from the traditional forms that are still present. Contemporary graffiti is a combination of writings and pictures, created mainly with new materials by young people in urban city spaces under their writer names. The level of aesthetic expression has also 
FIGURE 2: In the 798 art district in Beijing, 2007.

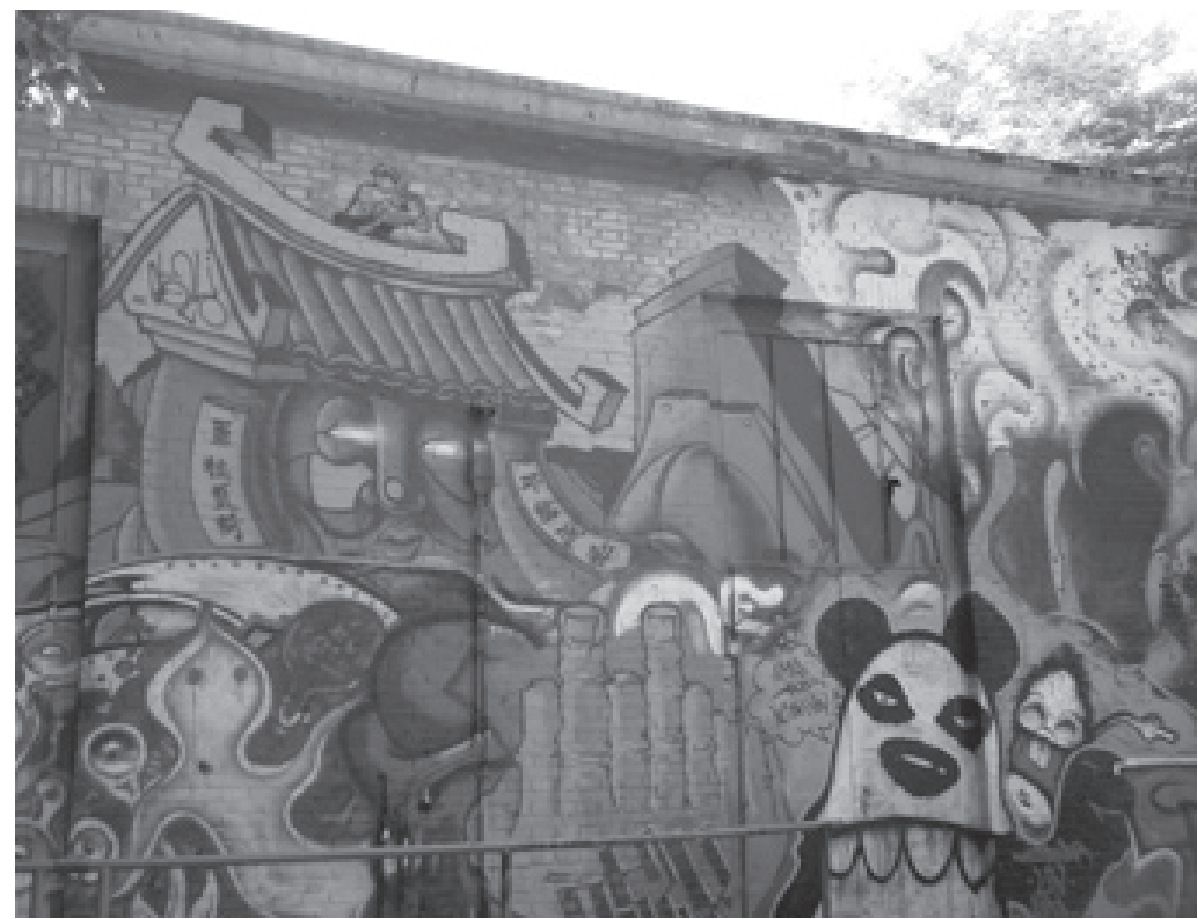

Copyright by the author.

grown and the subject-themes are more freely chosen by writers by combining stylistic elements from both Euro-American graffiti and Asian (especially Japanese) animation. Furthermore, graffiti has moved away from political participation and towards the beautification of the environment. Zhang Dali's graffiti originally was created as a visual dialogue to provoke awareness of urban change (Marinelli 2009: 33). Nevertheless, the new generation of writers mainly uses the walls as a canvas for artistic self-expression, creating graffiti images that often depict imaginary characters, such as ghosts, friendly dragons, animated mushrooms and cartoon characters. The majority of graffiti images, especially in Beijing are primarily pictures (see Figure 2). In Shanghai, many examples of wildstyle ${ }^{13}$ are visible, but they do not always have words as the major theme, but can be purely abstract expression based on lines and colours. These graffiti images are often aesthetically very compelling and carefully designed, and the majority of them clearly lack any specific social or political aim written/drawn in them. As such, the mostly non-political content indicates that the primary aim is beautification of the urban space, not rebellion. 


\section{Contemporary Chinese Graffiti as a Form of Art?}

Especially in recent years, the graffiti scene in China has become vivid and international. ${ }^{14}$ Due to the close interaction with the contemporary art scene since its emergence, the development of contemporary graffiti as a form of art clearly has been promoted. For Chinese writers, graffiti is, without doubt, a way to express themselves through graffiti images focusing on stylistic and aesthetic criteria. Style and originality are the most appreciated features in contemporary Chinese graffiti, just as they are on the Euro-American scene. As Jeff Ferrell states, graffiti 'must also be understood as an activity embedded in the aesthetic imperatives which develop among the writers' (1993: 53). Development of aesthetic expression has gradually transformed the understanding of modern graffiti from vandalism into a form of art since the $1970 \mathrm{~s}^{15}$ (see e.g., Castleman 1982: 116-133; Austin 2001: 70-74, 94-96). It has even been suggested that modern graffiti can be considered the most important art movement and the greatest art in the late twentieth century (Austin 2001: 6, 271).

However, one of the primary intentions of graffiti obviously has been to challenge the accustomed perceptions of artistic creation and art institutions. As such, it could fit well into the modern art scene rebelling against the traditions of fine art in the United States, along with avant-garde and feminist art. On the other hand, the intentions of writers to blur the distinctions between low and high culture could be considered to echo the aims of postmodern art movements such as pop and conceptual art. ${ }^{16}$ Besides the fact that modern graffiti was something completely new for trendy art lovers, it is likely that the similarity in intentions with the other contemporary art forms was one of the reasons why the art scene was enchanted by modern graffiti. It is nevertheless important to bear in mind that modern graffiti was - and still is - part of a far larger cultural phenomenon, at least in the Euro-American context. Therefore, it closely interacts with other forms of subculture, such as hip-hop music, skateboarding, and b-boying. By nature, modern graffiti does not aim to be included in art institutions or to be considered as fine art per se. As René de Guzman and Thom Collins (2004) have aptly pointed out, writers are often involved in various creative activities, which blurs the edge between graffiti and art even further: 'They sustain independent systems of creation, display and reception that only occasionally intersect with the field of the fine arts' (de Guzman and Collins 2004: 23; for further information on these forms of interaction, see Rose and Strike 2004). 
Whether modern graffiti can be regarded as popular art, street art, urban art or contemporary art cannot be strictly determined because it is a multilayered and continuously changing phenomenon. Furthermore, these definitions vary according to the sociocultural context, the content of graffiti, as well as the site where it appears. If an aesthetically compelling graffiti image is made on a canvas and displayed in a gallery, it is likely to be seen as a representative of contemporary art. However, the very same image on a wall in an urban environment is considered street art or urban art at its best, not contemporary art. What is essential to remember is that for the writers it does not necessarily matter whether the larger audience sees graffiti as any form of art; they will nevertheless continue their artistic endeavours, and primarily outside of the traditional art institutions.

Whether graffiti is considered vandalism or art in China is an intriguing question. Graffiti is usually referred to using the colloquial word tuya (涂鸦) which actually means 'poor handwriting', or 'to scrawl'. The original meaning gives a negative connotation to graffiti. Besides graffiti, tuya also is used to refer to small children's doodling. Interestingly, in the local press, contemporary graffiti is quite often referred to as 'graffiti art' (tuya yishu 涂鸦艺术), or occasionally, 'graffiti painting/ drawing' (tuya huihua 涂鸦绘画) or as a form of 'street art' (jietou yishu 街头艺术) (see e.g., Zhao 2007; Chen 2003; Li and Lai 2006). However, negative expressions are also related to graffiti and it is even referred to as 'psoriasis' (niupixuan 牛皮癣) (Chu 2007). Nevertheless, it seems that these more degrading expressions are used for the incised names, painted phone numbers and other scribbled texts and their cover-ups. The concepts of tuya yishu and tuya huihua are used to emphasize that the topic of discussion is graffiti in its contemporary form, emphasizing aesthetic features and including both pictures and writings, not the scribbled inscriptions or the children's doodling.

Writers themselves use the word pen (喷) as a verb to mean 'making of a graffito'. As a result, penzi (喷子) is equivalent to a 'writer' in English. More commonly, however, they refer to themselves using the English concept of a 'writer' or tuyazhe (涂鸦者), literally meaning 'a person involved in graffiti' or 'graffitist'. Chinese publications do not usually use any of these, but instead, use 'graffiti artist' (tuya yishujia 涂鸦艺术家). The use of these concepts referring to art and artists in Chinese suggests that graffiti could be regarded as a form of art also among the wider population. For all the writers I have met, graffiti definitely is an art form, a way of expressing oneself with beautiful graffiti images (flowerzzz, email message to author, 
14 June 2008; Rois, interview, 29 June 2008; Somo, interview 29 June 2008 ${ }^{17}$; Soos, interview, 13 June 2008; Zhang, interview, 20 June 2008).

Although in the United States and Europe graffiti gradually and partially has come to be regarded as a form of art (see e.g., Rahn 2002: 9), in China the relationship between art and graffiti seems to be somewhat different. Whereas in the Euro-American countries graffiti has slowly gained the social support of the art world, the Asian art world has accepted graffiti far more easily (Lally 2007). Based on my own observations, I would suggest that the development of the graffiti scene, at least in Beijing and Shanghai, has been strongly supported by the contemporary art scene from the beginning and therefore it has come to be regarded primarily as a form of art, at least among writers.

As already mentioned, the initial connection between art and graffiti was made by Zhang Dali. For him, graffiti was, and still is, clearly a form of art (Zhang, interview, 20 June 2008). His series Dialogue is regarded as contemporary art and displayed both in international and Chinese art exhibitions. In Zhang's work, graffiti inevitably changed into contemporary art, which in turn gained publicity for graffiti. Even today, Zhang continues to appreciate graffiti as a form of self-expression. He claims that for young urban people it is an important form of creativity and should be tolerated (Zhang, interview, 20 June 2008).

Another factor of the close interaction between contemporary art and graffiti in China is the existence of the internationally famous contemporary art areas in Beijing and Shanghai. In Beijing, the well-known 798 art district (known also as Dashanzi, 大山子) is an interesting exception to public norms: inside the area, contemporary graffiti clearly is allowed to exist. It is, at least to some extent, tolerated by the officials and the management of the area, and usually it is not painted over. As a result, hundreds of graffiti images are made on the walls of this gallery area. Some graffiti has been visible for over a year, which clearly shows that there is no systematic programme to paint over them. The rarity of covering up the graffiti by painting over it, which occurs in other urban areas, supports the claim that the art areas are regarded differently from other public urban space by the officials. However, especially beginning in spring 2008, because of the upcoming Olympic Games, graffiti was not tolerated as freely as it had been before. Consequently, writers did not go there as often as they used to but nevertheless, numerous graffiti images were still visible in the 798 art district in June 2008. After the Olympics, the situation relaxed again and even more vigorous graffiti was visible in June 2009. 
Graffiti is also visible in other art areas in Beijing such as Caochangdi (草场地) and the 'Old Wine Factory' (Jiuchang 酒厂), but not with the same vigorousness as in 798. Jiuchang and Chaochangdi are farther from the city centre and less known to tourists. Obviously 798 is the most supervised gallery area in Beijing because it has become the most popular among both Chinese and foreign visitors. If graffiti was not tolerated by the authorities, it would be more logical to find it in the art areas that are not so strictly supervised. In practice, however, 798 is the most popular space among writers, which therefore indicates that graffiti is somewhat tolerated in this art area. This fact also reveals the importance of fame and visibility for graffiti: the 798 art area is the best place to be seen by a large audience. Moreover, changes in the popularity of art areas are clearly influential for the emergence of graffiti. In 2009, due to the economic setback, which also slowed down the contemporary art scene in Beijing, gallery activities were reduced, especially in Jiuchang. According to my own observations, graffiti was also less visible in this area than during the previous year.

Interestingly, the opposite change has occurred in the neighbourhood of the Today Art Museum (Jinri Meishuguan 今日美术馆), in southern Beijing. In 2008 there were a few walls with some graffiti in the neighbourhood, but in 2009 a long wall running next to the enlarged museum compound was completely filled with graffiti. Naturally, spaces popular among the writers change according to various factors, and according to Soos, the neighbourhood of the Today Art Museum has become the best site for graffiti in Beijing (Soos, email message to author, 29 March 2010).

A rather similar co-existence of contemporary art and graffiti is also visible in Shanghai. In the famous gallery area of Shanghai, Moganshan $\mathrm{Lu}$ (莫干山路), and its close neighbourhoods, dozens of large graffiti images have been visible. Interestingly, most of them are not in the area itself, but on the wall by the Moganshan Road leading to the gallery area. This long wall has become the local 'wall of fame ${ }^{18}$ and it is completely filled with graffiti. Graffiti can also be found in the alleys close by, but it is found mostly along this road and therefore easily visible to a majority of the visitors that arrive by car to the art area.

To some extent contemporary graffiti exists in other areas both in Beijing and Shanghai, but the abundance of the graffiti in or around the neighbourhoods of art areas is remarkable. The tolerated status of graffiti in these areas is significant. Obviously, making dozens of large pieces around Moganshan $\mathrm{Lu}$ is not regarded as offensive, nor is it in 
the 798 art district in Beijing. The Shanghainese writer Popil refers to Moganshan Lu as a more open space, where creating graffiti is allowed (Schokora \& Xiang 2008). It could also be that by allowing contemporary graffiti to exist in the art areas, officials are guiding the development of graffiti so that it emerges as a form of street art or even community art, hoping to keep it from being transformed into a form of political rebellion. Nevertheless, the tolerance of graffiti images is clearly related to these areas being regarded as a kind of 'open creative space'.

The second method used by the contemporary art scene to support the development of contemporary graffiti, besides providing an openair space, is to organize graffiti events and exhibitions. For example, in June 2006 the exhibition 'A Story of Graffiti...' was organized in a warehouse space called Factory at Kangding Road, featuring both foreign and Chinese writers (Kinzbro 2007; Lally 2007: 149). In Beijing, a graffiti exhibition was arranged in the Must be Contemporary Art gallery in 798 in April 2007. Furthermore, the Red T gallery, which was open in 798 until March 2008, arranged two 'Graffiti Parties', the first on 10 May 2007 and the second on 1 March 2008. At the first one, three writers who formed a crew called Beijing Penzi (BJPZ 北京喷子), were invited to paint a graffito on a large building board which was placed in front of the exhibition space. The second one was organized by the Red T gallery as a 'De-Face' party preceding the demolition of the gallery. People were invited to use the bare walls of the gallery as a canvas for artistic creation (Tamsin Roberts, email messages to author, 27 March, 9 May and 12 May 2008; see also Ribbons 2008; Chung 2008). Moreover, a solo exhibition by Banksy, an internationally known British writer, was arranged at the Schoeni Art Gallery in Hong Kong in 2008 (Schoeni Art Gallery 2009). Although the graffiti exhibitions are not continuously arranged, and compared to the vivid exhibition scene are a marginal phenomenon, they nevertheless show that the contemporary art scene is interested in graffiti, and supports its recognition as a form of art.

Other factors that express the relation of art and graffiti can be found in the artworks themselves. Some artists have explored the styles of graffiti in their works, and many well-known writers are actually pop artists (flowerzz, email message to author, 14 June 2008). A majority of the writers are actually art students, designers or otherwise connected with creative industries. ${ }^{19}$ Chinese writers also create contemporary artworks in the style of graffiti on canvas or on objects. In addition, they use other temporary surfaces for graffiti such as cardboard boxes and chipboard. Creating on surfaces other than public walls transforms 
graffiti into an even more easily acceptable form of art, because it is not destroying public property anymore.

In practice, the questions of art, graffiti and graffiti art in today's China are strongly intertwined and the boundaries have been blurred. Graffiti workshops, competitions and events have been organized in growing numbers outside of art areas with official permission, while the art scene, writers and even popular journals are advocating contemporary graffiti as a form of art. Whether it is considered art in public opinion is one of the questions that would require further research. Based on my research, I suggest that because contemporary Chinese graffiti was introduced to the public primarily as a form of art at its emergence, it is more acceptable for Chinese citizens to consider it as art rather than vandalism.

\section{Motivation and Graffiti Images}

Besides the support of members of the art scene, actions of the writers themselves and the content of graffiti images affect public and official opinion on contemporary graffiti. Especially in the United States, the emergence of the graffiti culture was often connected with gangs, criminality, drugs and the hip-hop culture. Consequently, graffiti has been regarded both as a sign and an accelerator of urban decay, and therefore it had to be erased regardless of the costs (see e.g., Castleman 1982: 134-157; Austin 2001: 33-37, 63-65). The commonly shared notion that graffiti is primarily illegal vandalism that promotes criminality and must be countered with harsh punishment is not necessarily appropriate to graffiti in the Chinese sociocultural context. As indicated by John Clark (1998), when a visual system is transferred from one culture to another, even the forms of the visual system can be transformed for other purposes (Clark 1998: 35-37). In addition, as Harris (1995) has advocated, forming and processing are clearly interdependent activities depending on the communicational context. In the context of contemporary graffiti in China, both of these implications have been highly relevant.

The motivation to create graffiti, how it is made, and what the content is, directly interact with official and public reactions, the processing of the meaning. If the writers consider graffiti primarily as a sign of political activity, officials would react accordingly. Chinese writers state that political slogans or anti-government graffiti images would have severe consequences (see e.g., Lipman 2007). Similarly, choosing the location is highly relevant, and even the attempt to write one's tag on the Maglev 
train or in the internationally famous leisure area of Xintiandi (新天地) in Shanghai would surely have negative consequences. As the Shanghainese writer Somo clarified, officials have a tolerant attitude toward writers if they do not get too visible or if the graffiti is not too offensive (Somo, interview, 29 June 2008). For example, the 'bombing ${ }^{120}$ of trains, which has been very popular in the Euro-American countries (see e.g., Cooper \& Chalfant 1984: 69-79; Macdonald 2002: 108-109) is still rare in China. Occasionally it has been done by writers in the southern cities, but according to Soos, this is extremely rare because writers just do not want to get into so much trouble (interview, 13 June 2008). The visibility referred to by Somo also applies to the amount of graffiti in public space. If Chinese writers would start to tag and bomb everything, the situation would obviously change and officials would not be so tolerant. At the moment, the scarcity of tags in public transportation or in other public spaces (except in the contemporary art areas) is still a remarkable feature of the Chinese graffiti scene.

In China, at the moment, the majority of writers deliberately seem to still avoid graffiti as a political action or statement. Besides, Chinese writers strongly deny any criminal aspects related to graffiti, which on the contrary, are still promoted occasionally among Euro-American writers. Furthermore, the attitude towards commissioned and paid graffiti is usually more positive among Chinese writers, as opposed to claims of some Euro-American writers that only illegally created graffiti is true graffiti. For example, in London and New York, graffiti clearly is regarded as a fight against the officials. For many writers, illegality is the crucial definition for graffiti, and a pre-ordered piece is not graffiti (Macdonald 2002: 94-150). Similar notions of 'keeping it real' by creating illegal graffiti, not commissioned graffiti, are often expressed (see e.g., Rahn 2002: 20, 175-180). My own observations, however, suggest a very different situation in China. Writers do not consider graffiti as vandalism, a criminal act nor a manifestation of class struggle.

Obviously, writers of any country are not a homogeneous group and although beautification is emphasized among some writers in Beijing, Shanghai and Hong Kong, for others, graffiti might also be a way to reveal social anxiety. Interestingly, according to the British Broadcasting Corporation (BBC 2002), Chinese graffiti can clearly be seen as a social statement and expressions such as 'leave me alone!' and verbal attacks on the local authorities are common (Chen 2007). Although I have been informed that some writers are becoming more daring and they do use political expressions, I have not personally seen this kind of writing in 
Beijing or in Shanghai yet. However, some graffiti images clearly reveal social anxiety or criticism. Graffiti obviously reflects the society, but it is also important to remember that a social comment is not necessarily a political statement. The most political statement I have found was a bilingual piece 'One China Forever 壹個中國' at Moganshan Lu. It is of course possible that political statements would be painted over quickly by the officials, but according to my observations and comments from the writers, expressing political opinions is very rare and primarily avoided. Naturally, as Schacter clarifies, the very act of creating graffiti can be seen as a political action because of its illegality (Schacter 2008: 50). However, for Chinese writers, the aspect of artistic self-expression is a primary objective of graffiti images at the moment, not political action. Naturally, the situation can vary among different cities, crews and individuals, and therefore further research on motivation among writers in China would be needed for deeper understanding of the phenomena. Here I wish to make the point that to assume graffiti images are made with the same intentions as in the Euro-American context would be a naive hypothesis.

Whether graffiti is illegal is actually an unclear issue. Some writers claim it is illegal, but others say that there is no specific law against it (Dezio, email message to author, 3 November 2010; Popil, email message to author, 14 March 2011; Loomit, interview, 5 July 201021). In practice, there are no harsh punishments against graffiti in China. If caught in the act of writing graffiti, the writer can be fined or asked to wash away or paint over the graffiti by police. However, it seems that the situation is not as strict as it is, for example, in the United Kingdom or in Finland. The fines are much lower, and to my knowledge, no one has been sentenced to prison for doing graffiti in China. Occasionally, some writers have been detained for a few hours or overnight. Although Chinese writers protect their identity to some extent, they are not as cautious as one might assume, which also indicates that they are not actively sought out by the officials. Nowadays the most daring writers in China even write their email addresses on the walls and some post videos on YouTube or give interviews to the local press without hiding their faces. Originally, Zhang Dali was very careful to protect his true identity and in interviews he appeared under his writer name 'AK-47' and wore sunglasses (see e.g., Zhang 1999; Fathers 1999: 40), but today he is widely known. This suggests that although graffiti in China is a controversial issue, it is not, at the moment, considered a very serious crime or form of vandalism. 
Interestingly, officials may even support the emergence of contemporary graffiti by occasional commissions. For example, before the Olympic Games writers were asked to make graffiti images around Beijing. As an example, the 'cultural wall of Beijing Olympics' (Beijing Ouyun Wenhua Qiang 北京欧云文化墙) was established and filled with large pieces in the neighbourhood of the 798 art district. This wall was still visible and intact in June 2009. However, graffiti of this 'official' kind is not always appreciated among the Chinese writers (Soos, interview, 13 June 2008; flowerzzz, email message to author, 14 June 2008). What makes this phenomenon highly interesting is the fact that officials were using contemporary graffiti to improve the image of the city and, in the case of Beijing, the whole nation. By accepting graffiti to some extent and even supporting it in these certain sites, Chinese officials are promoting a more flexible and tolerant image of themselves regarding self-expression and urban youth cultures. Similarly, to create a positive image of the city, graffiti has been used in Chongqing, where several blocks of apartment buildings on Huangjueping street have been completely covered with graffiti (Han 2007).

Accepting paid commissions, choosing non-political imagery and creating graffiti images in areas in which it is tolerated by officials, strengthen the fact that Chinese writers, at the moment, are not emphasizing illegality as a primary feature of graffiti. On the contrary, it can be concluded that due to the various communicationally significant features of the forming process, such as the amount, content, motivation, and place used, contemporary graffiti in China, at the moment, is not considered as a war against the officials or as illegal political guerrilla action by the writers or the public.

As discussed, the stylistic features are also important for evaluating motivations and the development of graffiti. Chinese graffiti is based on Euro-American graffiti and consequently, various visual elements and styles are absorbed on the Chinese streets. While every writer aims to develop his or her own individual style, writers also occasionally express their wishes to develop a specific 'Chinese style' (Soos, interview, 13 June 2008; Schokora \& Xiang 2008). However, what might represent 'Chineseness' is an intriguing question that even the writers are not yet able to answer. One might naturally expect that the use of Chinese language would be a distinguishable feature. Pieces with Chinese characters do exist in growing numbers, but they are not very common yet. The majority of graffiti, if they include any words, are written in English, because Euro-American graffiti found on the Internet is used as models. 
FIGURE 3: In the 798 art district in Beijing, 2007.

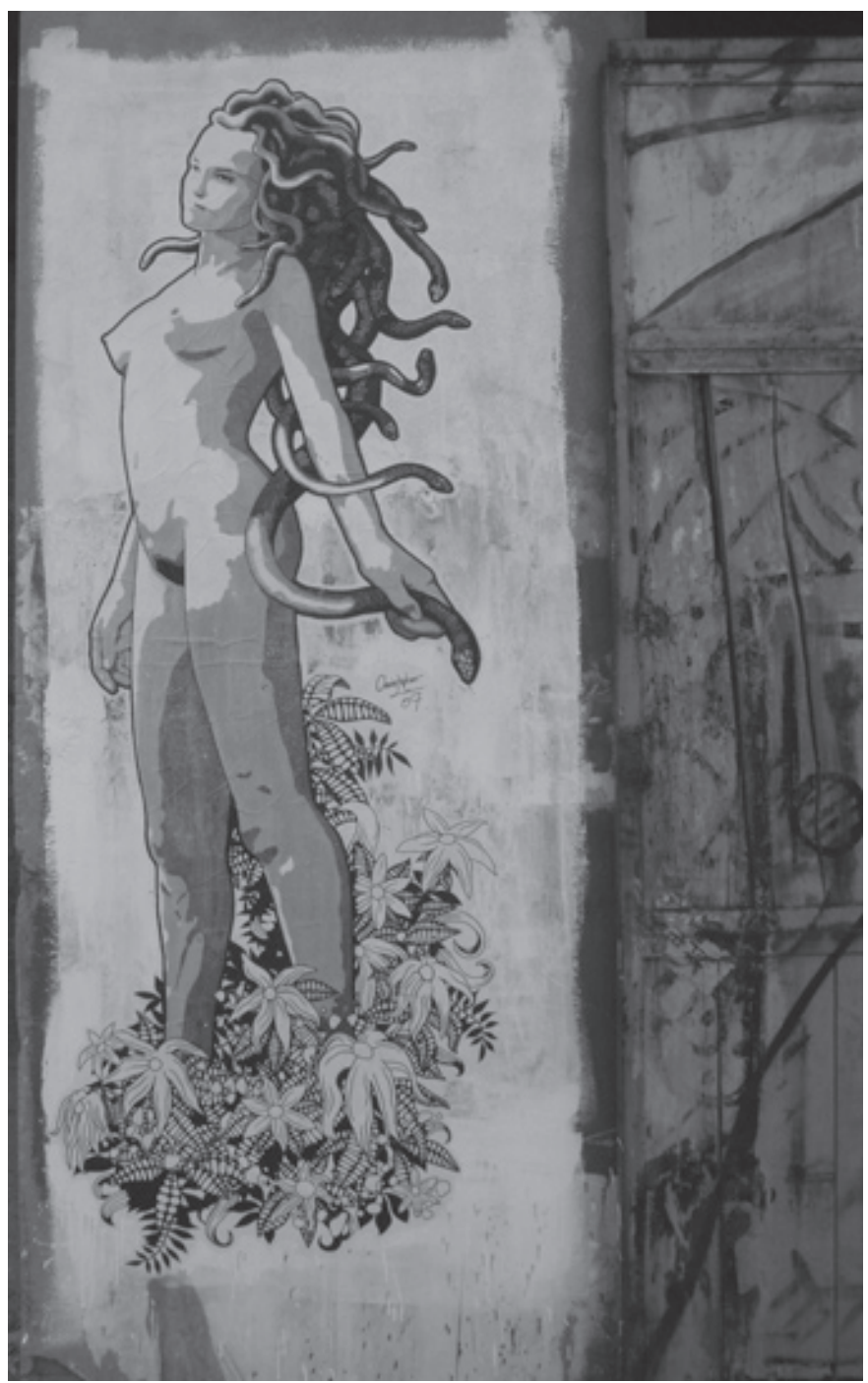

Copyright by the author.

One reason for not using Chinese characters is related to the question of style. According to writers themselves, Chinese characters become easily illegible if written in a vigorous wildstyle and therefore English is still preferred (Soos, interview, 13 June 2008; Rois, interview, 1 July 2008). However, very elaborate examples of Chinese text in wildstyle are increasingly created. Consequently, this enhances the adaptation of graffiti as part of the urban Chinese culture.

Graffiti in China is international, especially in Shanghai, and non-Chinese writers actively participate in the scene and organize graffiti events 
(Dezio, email message to author, 3 November 2010; Loomit, interview, 5 July 2010). It is therefore important to bear in mind that not all the graffiti visible in China is made by Chinese writers. Occasionally, according to language or visual aspects (such as imagery, technique and subject-matter), it is possible to determine whether the graffiti is done by a foreign or Chinese writer. As in Figure 3, due to various features, I suggest, that the writer is not Chinese. First, the subject-theme, Medusa, might be familiar to Chinese, but it is more likely to be a theme chosen by a Western writer. Second, the format used, a poster glued to the wall, which is evident due to the small wrinkles caused by the paper, is a rather new format in graffiti, and not yet often used by Chinese writers. Third, the eloquently and skilfully depicted nude female body suggests a high level of artistic training, especially with drawing nudes. It is naturally possible for a Chinese art student to achieve this level, but since displaying nudity in public is still somewhat restricted in the Chinese art scene, it is more likely that this was posted by a Westerner. Fourth, the signature, 'Christopher' could perhaps be adapted by a Chinese writer, but usually they do not choose Western names. Finally, the stylistic way of writing the number seven confirms that this is most likely done by a Westerner as the Chinese way of writing ' 7 ' is done without the line in the middle. As such, this kind of processing, which Harris says includes any activities 'by means of which the written form is then examined for purposes of interpretation' (Harris 1995: 64-65), reveals even the importance of the typography used in graffiti.

\section{Conclusion}

Despite the long tradition of writing in public in China, the contemporary form of graffiti did not appear until socio-political and cultural changes allowed new art forms to be developed in the contemporary art scene inspired by the impact of international art forms. In recent years, the graffiti scene in China has become a vigorous phenomenon. Although Chinese contemporary graffiti derives from Euro-American graffiti, its forming and processing are nevertheless socioculturally dependent, and therefore the situation is not similar to other countries. One major difference is that graffiti is not regarded primarily as vandalism by writers, officials or in public opinion, at least as long as it appears in certain areas and without clear political content. It could be pondered whether officials have adopted a limited tolerance towards graffiti to prevent it from becoming a serious political problem. It seems that these 
semi-illegal graffiti spaces, such as art areas, act as a safety valve: officials do not completely deny contemporary graffiti as creative self-expression, but they, in a way, guide its existence and development. Basically, this pre-supervision restrains to some extent the contemporary graffiti from transforming into undesired forms at the moment. The art areas have become regarded as a somewhat 'open creative space' both by the officials and the writers themselves.

As I have discussed, graffiti can be regarded as a form of artistic self-expression and as a form of art in China. Despite the obvious lack of documentation and research, there is a vivid and developing graffiti scene in several Chinese cities. In Beijing, Shanghai and maybe even in Hong Kong, it has been strongly supported by the contemporary art scene. Furthermore, graffiti images have become an essential part of visual culture, where the cultural meanings are constructed in an intertextual sphere. Graffiti images in China have been displayed as art in the contemporary art scene, and they include characters from cartoons and films. This multifaceted interaction, as well as the situation of contemporary graffiti in other Chinese cities, would be interesting issues to be addressed by further studies. According to my observation, it is nevertheless important to take into account both the writers' own opinions and the imagery used in graffiti to understand what is really happening on the urban walls. The visual aspects and the content of the graffiti are extremely important factors, which strongly impact the significance of graffiti as a social phenomenon for both writers and the public. They can also reveal various aspects of the act of forming, in relation to identity and motivations. Do Chinese writers prefer to advocate a notion of 'Chineseness' with a distinctive style? What kind of female images are created? Are there differences in images depending on the gender of a writer? These are all highly interesting questions that could be investigated with comparative research based on visual analysis of graffiti images.

Minna Valjakka, PhD, is a researcher of Chinese visual culture in Art History at the University of Helsinki. She is building up a database-related pool of digital images on graffiti in China in the context of the Heidelberg Research Architecture at the Cluster of Excellence 'Asia and Europe in a Global Context', Heidelberg University. (minna.valjakka@helsinki.fi) 


\section{NOTES}

1 A 'writer' is a person who creates graffiti.

2 A 'tag' is a designed signature of a writer's name, usually made with a marker pen and in rather small size.

3 Schacter borrows the concept of 'distributed personhood' from Alfred Gell. For further information, see Gell 1998.

4 See especially the diagram in Elkins (1999), p. 85.

5 See the image in Wang (2007), p. 32.

6 'Tagging' refers to the act of writing 'tags'.

7 'Piece' is short for masterpiece, which is a large multicoloured mural with detailed design, including both text and pictures or only text or only a picture.

8 'Throw-ups' are quite large and quickly made tags. Usually the outline of the letters is made with a different colour than that which is used for filling up the letters.

9 Rois, Chinese writer, unpublished interview with the author in Shanghai.

10 Zhang Dali, Chinese contemporary artist, unpublished interview with the author in Beijing.

11 Soos, Chinese writer, unpublished interview with the author in Beijing. Soos is a writer name like Somo, Rois and flowerzzz. To protect the writers' identities I did not even ask their real names.

12 The nickname was given to Tsang Tsou Choi by the media, but according to visual material, he did not use it to sign the writings.

13 'Wildstyle' is a specific style used usually in pieces. It includes highly modified, complex and interwoven letters and can therefore be difficult to read.

14 Chinese writers are familiar with the English slang of graffiti, and they use it during conversation in Chinese. Chinese writers and crews also have their own web pages, but some are actively involved with international graffiti web pages. (See e.g., Art Crimes, Streetfiles, Pure Graffiti.) Moreover, Chinese writers post videos on the YouTube web page (see e.g., detroitshowtyme 2007; DJLouEngine 2007; yak457 2007).

15 For example, organizations such as United Graffiti Artists (UGA) and Nation of Graffiti Artists (NOGA) encouraged American writers to explore their talents on canvas and gradually become graffiti artists.

16 The definitions of different art movements and whether they are representatives of modern or postmodern art are far too complicated to be discussed in this paper.

17 Somo, Chinese writer, unpublished interview with the author in Shanghai.

18 The 'wall of fame' is a wall filled with graffiti by various writers.

19 The writers I interviewed were involved in some designing projects or planning to have their own design studios. The common interest to design everyday products is also clearly visible on writers' blogs and web pages. See e.g., the web pages of Kinzbro, Popil and CathLove.

$20 \mathrm{To}$ 'bomb' is to cover something completely with graffiti.

21 Dezio, French writer living in Shanghai. Popil, Chinese writer in Shanghai. Loomit (Mathias Köhler), German writer in München, unpublished phone interview with the author. 


\section{REFERENCES}

56minus1. 2008. 'Guangzhou graffiti.' Available from: <http://www.youtube.com/ watch?v=sgurb9W_C18>, accessed 10 November 2009.

Art Crimes. The Writing on the Wall. 2008. http://www.graffiti.org, accessed 28 September 2008.

Austin, J. 2001. Taking the Train. How Graffiti Art Became an Urban Crisis in New York City. New York: Columbia University Press.

Barthelmeh, V. 1982. Street Murals. New York: Alfred A. Knopf.

Baudrillard, J. 1993. Symbolic Exchange and Death. London: Sage.

Borysevicz, M. 1998. 'Zhang Dali's Conversation with Beijing'. ART AsiaPacific 22: 52-58.

Borysevicz, M. 2008. 'Off the Wall'. Modern Painters May 2008: 68-71.

Brewer, D. D., and M. L. Miller. 1990. 'Bombing and Burning: The Social Organization and Values of Hip Hop Graffiti Writers and Implications for Policy.' Deviant Behavior 11(4): 345-369.

British Broadcasting Corporation (BBC). 2002. 'Graffiti's Wrecking China's Great Wall'. 17 July 2002. http://news.bbc.co.uk/cbbcnews/hi/world/newsid_2133000/2133957. stm.

Caffee, L. G. 1993. Political Protest and Street Art. Popular Tools for Democratization in Hispanic Countries. Westport, CT and London: Greenwood Press.

Castleman, G. 1982. Getting Up. Subway Graffiti in New York. Cambridge: MIT Press.

CathLove. 2008. http:/ / www.cathlove.com, accessed 1 October 2008.

Chen, D. 2007. 'In Pictures: Graffiti Artists in Beijing'. BBC [online]. http://news.bbc. co.uk/2/shared/spl/hi/picture_gallery/07/asia_pac_graffiti_artists_in_beijing/ html/1.stm.

Chen, J. 2003. 'Shangye shehui yu tuya yishu'. [Commercial society and graffiti art] Xibei Meishu. [Northwest Fine Arts] 2: 8-9.

Chu, S. 2007. 'The Original Pictures of "City Tattoo" '. http://www.lifeofguangzhou. com/node_10/node_35/node_116/node_610/2007/04/30/117790098519013.shtml, accessed 11 November 2009.

Chung, D. 2008. 'A dash through Dashanzi'. Arts Guardian [online]. http://www. guardian.co.uk/arts/video/2008/mar/14/dashanzi.

Clark, J. 1998. Modern Asian Art. Honolulu: University of Hawaii Press.

Clarke, D. 2002. Hong Kong Art. Culture and Decolonization. Durham: Duke University Press.

Clarke, D. 2001. 'Subaltern Writing: Tsang Tsou Choi: The King of Kowloon'. ART AsiaPacific 29: 69-71.

Clunas, C. 2007. Empire of Great Brightness: Visual and Material Cultures of Ming China, 1368-1644. London: Reaktion Books.

Cooper, M., and H. Chalfant. 1984. Subway Art. London: Thames and Hudson.

detroitshowtyme. 2007. 'Chinese Graffiti Beijing - Li Qiu Qiu' (video). http:/ / nz.youtube. $\mathrm{com} /$ watch? $\mathrm{v}=\mathrm{tv} 29 \mathrm{PjfI}-6 \mathrm{o}$.

Dikovitskaya, M. 2005. Visual Culture: The Study of the Visual after the Cultural Turn. Cambridge, MA: MIT Press.

DJLouEngine. 2007. 'KaoBook Crew from China Graffiti' (video). http://nz.youtube. $\mathrm{com} /$ watch? $\mathrm{v}=\mathrm{tfVTo} 2 \mathrm{PkU}$ oU.

Elkins, J. 1999. Domain of Images. Ithaca: Cornell University Press.

Elkins, J. 2003. Visual Studies: A Skeptical Introduction. New York: Routledge.

Fathers, F. 1999. 'Democracy Walls'. Asiaweek 25(16): 40.

Feiner, J., and S. M. Klein. 1982. 'Graffiti Talks'. Social Policy 12: 47-53. 
Ferrell, J. 1993. Crimes of Style: Urban Graffiti and the Politics of Criminality. New York \& London: Garland Publishing.

Freundl, D. 2008. 'Vandal or VanGogh. Mine \& Zoolo'. all - Da Meishu [all - Great Art]. 1: 134-137.

Galikowski, M. 1998. Art and Politics in China 1949-1984. Hong Kong: The Chinese University Press.

Ganz, N. 2004. Graffiti World: Street Art from Five Continents. New York: Harry N. Abrams.

Gao M. 2005. The Wall: Reshaping Contemporary Chinese Art. 中国当代艺术的历史与边界. [Zhongguo Dangdai Yishu de Lishi yu Bianjie.] Buffalo, NY: Albright Knox Art Gallery, University at Buffalo Art Galleries \& Beijing: Millennium Art Museum.

Gastman, R., C. Neelon, and A. Smyrski. 2007. Street World: Urban Culture and Art from Five Continents. London: Abrams Books.

Gell, A. 1998. Art and Agency: Towards an Anthropological Theory. Oxford: Clarendon Press.

Gordon, A. 2002. 'The Act of Libel: Conscripting Civic Space in Early Modern England'. Journal of Medieval and Early Modern Studies 32(2): 375-397.

Grody, S. 2007. Graffiti L.A.: Street Styles and Art. New York: Harry N. Abrams.

de Guzman, R., and T. Collins. 2004. 'Introduction'. In Beautiful Losers: Contemporary Art and Street Culture, edited by A. Rose and C. Strike, 23-24. New York: Iconoclast, in conjunction with D. A. P.

Han, X. 2007. 'Go to Huang Jue Ping to Watch the Doodlestreet. Qu Huang Jue Ping, Kan tuya yishu jie'. Jinri Chongqing. [Chongqing Today] 22: 114-116.

Harris, R. 1995. Signs of Writing. London \& New York: Routledge.

Huber, J. 1986. Paris Graffiti. London: Thames and Hudson.

Jacobson, S. 1996. Den Spraymålade Bilden. PhD diss. Lund University. Lund: Aerosol Art Archives.

Journeyman pictures 2000. 'Beijing Graffiti - China' (video). http:/ /nz.youtube.com/ watch? $=$ BwsgZ52d7Kg.

Kinzbro. 2007. 'Ai-ya-ya' (blog). http:/ / kinzbro.blogspot.com, accessed 6 November 2009.

Lachmann, R. 1988. 'Graffiti as Career and Ideology'. The American Journal of Sociology 94(2): 229-250.

Lally, J. 2007. 'Emerging Voices. Graffiti Begins to Make its Mark in China.' all - Da

Meishu [all - Great Art] 7: 148-152.

Li, X., and T. Lai. 2006. 'Chengshi zhong de tuya yishu'. [Graffiti art in the city]. Zhongguo Meishuguan. [Museums of China] 5.

Lipman, E. 2007. 'Tag Team'. Time Out Beijing: 6-7.

Macdonald, N. 2002. The Graffiti Subculture. Youth, Masculinity and Identity in London and in New York. 2nd edition. New York: Palgrave Macmillian.

Marinelli, M. 2004. 'Walls of Dialogue in the Chinese Space'. China Information 18: 429-462.

Marinelli, M. 2009. 'Negotiating Beijing's Identity at the Turn of the Twentieth Century'. In Dissent and cultural resistance in Asia's cities, edited by M. Butcher and S. Velayutham, 33-52. London \& New York: Routledge.

MCRen 2007. 'Wo shi Yazhou tuya di yi ren.' [I am the first graffitist in Asia]. http:/ / www.nnstreets.com/bbs/viewthread.php?tid=113116\&extra=page\%3D1, accessed 1 October 2008.

Mirzoeff, N., ed. 2002. The Visual Culture Reader. 2nd edition. New York: Routledge. 
Mitchell, W. J. T. 1986. Iconology: Image, Text, Ideology. Chicago: University of Chicago Press.

Pearl Channel. 2007. 'Great Walls of China'. The Pearl Report. Pearl Channel of Television Broadcasts Ltd. Hong Kong (video).

Plesch, V. 2002. 'Memory on the Wall: Graffiti on Religious Wall Paintings'. Journal of Medieval and Early Modern Studies 32 (1): 167-197.

Popil. 2009. (blog). http://www.neocha.com/popil, accessed 5 November 2009.

Pure Graffiti. 2008. http://www.puregraffiti.com/, accessed 30 August 2008.

Rahn, J. 2002. Painting Without Permission. Hip-Hop Graffiti Subculture. Westport \& London: Bergin \& Garvey.

Ribbons, E. (aka cheekymonkeytheater) 2008. 'Make Art Not Carparks' (video). http:/ / nz.youtube.com/watch?v=rgnlEsLB3JA\&eurl=http:/ / www.iheartbeijing. $\mathrm{com} / \mathrm{blog} / \mathrm{p}=117$.

Rogoff, I. 2002. 'Studying Visual Culture.' In The Visual Culture Reader, edited by N. Mirzoeff, 24-36. 2nd edition. New York: Routledge.

Rose, A., and C. Strike, eds. 2004. Beautiful Losers: Contemporary Art and Street Culture. New York: Iconoclast, in conjunction with D.A.P.

Sanada, R. 2007. Rackgaki: Japanese Graffiti. London: Laurence King Publishers.

Sanada R., and S. Hassan. 2010. Graffiti Asia. London: Laurence King Publishers.

Schacter, R. 2008. 'An Ethnography of Iconoclash'. Journal of Material Culture 13(1): 35-61.

Schoeni Art Gallery 2009. http:/ / www.schoeni.com.hk, accessed 5 November 2009.

Schokora A., and G. Xiang. 2008. 'The Shanghai Beat: Graffiti Shanghai' (video). http:/ / www.youtube.com/watch? $=\mathrm{i}=\mathrm{kAPr} 9 \mathrm{R}-\mathrm{I}$.

St/Art. 2008. http:/ / www.start.hk, accessed 28 September 2008.

Stewart, J. 1989. Subway Graffiti. An Aesthetic Study of Graffiti on the Subway System of New York City, 1970-1978. PhD diss. New York University.

Streetfiles.org. An independent Street Art \& Graffiti photo community. 2009. http:// streetfiles.org, accessed 5 November 2009.

Tamsin, R. 2008. Red T. http:/ / tamsinroberts.com/, accessed 28 September 2008.

Wang, J. 2007. 反文化性在当代涂鸦艺术中的表现. [Fan wenhuaxing zai dangdai tuya yishu zhong de biaoxian. Graffiti art today resists culturalism with its expression.] Unpublished MA thesis. Hubei Institute of Fine Arts.

Wei, H. 2008. 涂鸦艺术在中国发展的可行性研究. [Tuya yishu zai Zhongguo fazhan de kexingxing yanjiu. Feasibility study of the development of graffiti in China.] Unpublished MA thesis. Huazhong Normal University.

Wu, H. 2000. 'Zhang Dali's Dialogue: Conversation with a City'. Public Culture 12(3): $749-768$.

yak457 2007. 'Graffiti in Beijing Wildside' (video). http://nz.youtube.com/ watch?v=ccn7EwBAsjY, accessed 25 September 2008.

Yu, H. 2009. Media and Cultural Transformation in China. London \& New York: Routledge.

Zhang, D. 1999. Zhang Dali: Demolition \& Dialogue. Zhang dali: duihua he chai. Beijing: Courtyard Gallery.

Zhang, Z. 2006. 'Should Cities Regulate Graffiti?' Beijing Review [online]. http:/ / www. bjreview.com/forum/txt/2006-12/18/content_51257.htm, accessed 30 September 2008.

Zhao, Y. 2007. '街头涂鸦和现代设计. ' ['Jietou tuya he xiandai sheji.' Street graffiti and contemporary design] Xibei Meishu [Northwest Fine Arts] 1: 13-14. 